\title{
Entrepreneurial Education in Engineering Curricula at the University of Toronto
}

\author{
A.T. Tran, J.D. Toupin and J.C. Paradi \\ Department of Chemical Engineering and Applied Chemistry, University of Toronto \\ angela.tran@utoronto.ca; justin.toupin@utoronto.ca; paradi@mie.utoronto.ca
}

The importance and implications of entrepreneurial education in engineering curricula have been welldocumented, leading to its rapid growth in many Canadian Engineering schools in recent years. For undergraduate students, this education promotes interdisciplinary and diverse thought with awareness of the political, financial and social environments that inevitably influence their careers and possible business initiatives on the local and/or global stage. For graduate students developing leading-edge technologies, this education encourages the much needed commercialization of innovations in Canada. However, in Canada, entrepreneurial education is often outsourced to business schools which emphasize theory over pragmatic real-world approaches. In contrast, top-tier engineering schools in the United States have easily identifiable entrepreneurship programs and/or courses.

We have developed a pragmatic entrepreneurial program designed for engineering students at the University of Toronto (UofT). In particular, two aspects of the program have been critical to the program's success. First, all courses within the program involve a true-to-life business plan project in which students are pushed to come up with and develop their own business idea to the level of quality expected in the "real world". Second, the curriculum is delivered by practicing entrepreneurs who lecture in the context of their own experiences with the majority of the lecturers being pulled in from outside of the faculty. The result is a program focused less on theoretical work and more on the opportunities and obstacles likely to be encountered in an entrepreneurial career. Further, three versions of the program are offered in order meet the varied needs and interests of the student body. In particular, two undergraduate courses are taught concurrently with one being a more in-depth exploration of entrepreneurship that spans across two semesters and another abridged course that runs over one semester. A graduate-level version of the course is also taught and focuses on how to commercialize intellectual property developed through graduate student research.

Our program has evolved over more than 20 years. Over this time, we have identified weaknesses and opportunities for improvement. For instance, engineering students appear to have difficulty with marketing and the financial aspects of the business. We plan to address this by implementing case studies of business plans. Students also have difficulty with creatively identifying business opportunities which may suggest a potential issue with the focus of engineering education in general. Nonetheless, our program has been successful with students, in terms of their satisfaction as well as in their business formation and value/wealth creation after graduation. Students have consistently scored the program, on exit surveys, as having delivered unique material - illustrating that it is filling an educational gap in the engineering curriculum at the UofT. Consequently, this program has been extremely popular; we currently serve 180-200 students each year out of the many who apply. With such demand exceeding our capacity, plans for expansion are underway and are expected to run smoothly as the program is purposely designed in modules to make the courses easy to "clone", and for new instructors to be trained quickly. Moreover, we see potential for other faculties at the UofT and other universities to adopt and modify our model to suit their future needs. 